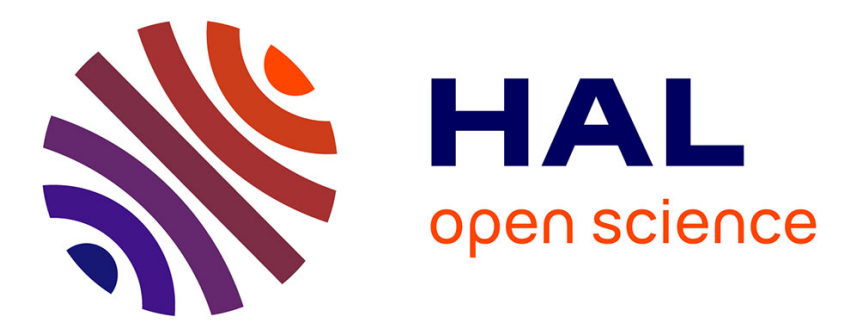

\title{
Analysing Product Development Process and PLM Features in the Food and Fashion Industries
}

Elisa D'avolio, Claudia Pinna, Romeo Bandinelli, Sergio Terzi, Rinaldo

Rinaldi

\section{- To cite this version:}

Elisa D'avolio, Claudia Pinna, Romeo Bandinelli, Sergio Terzi, Rinaldo Rinaldi. Analysing Product Development Process and PLM Features in the Food and Fashion Industries. 14th IFIP International Conference on Product Lifecycle Management (PLM), Jul 2017, Seville, Spain. pp.509-521, 10.1007/978-3-319-72905-3_45. hal-01764186

\section{HAL Id: hal-01764186 \\ https://hal.inria.fr/hal-01764186}

Submitted on 11 Apr 2018

HAL is a multi-disciplinary open access archive for the deposit and dissemination of scientific research documents, whether they are published or not. The documents may come from teaching and research institutions in France or abroad, or from public or private research centers.
L'archive ouverte pluridisciplinaire HAL, est destinée au dépôt et à la diffusion de documents scientifiques de niveau recherche, publiés ou non, émanant des établissements d'enseignement et de recherche français ou étrangers, des laboratoires publics ou privés.

\section{(c)(1)}

Distributed under a Creative Commons Attribution| 4.0 International License 


\title{
Analysing Product Development process and PLM features in the Food \& Fashion industries
}

\author{
Elisa d'Avolio ${ }^{1}$, Claudia Pinna ${ }^{2}$, Romeo Bandinelli ${ }^{1}$, Sergio Terzi $^{2}$, Rinaldo Rinaldi ${ }^{1}$ \\ ${ }^{1}$ University of Florence, Department of Industrial Engineering, Florence, Italy \\ elisa.davolio@unifi.it, romeo.bandinelli@unifi.it, \\ rinaldo.rinaldi@unifi.it \\ ${ }^{2}$ Politecnico di Milano, Department of Management, Economics and Industrial \\ Engineering, Milan, Italy \\ claudia.pinna@polimi.it, sergio.terziepolimi.it
}

\begin{abstract}
The food and fashion industries are well-known as areas of excellence representing Italy globally. Their products include innovative features, have short lifecycles and a high level of customisation. Both the pipelines have to respond quickly to unpredictable demand in order to minimize stock-outs, forced markdowns, obsolete inventory and they focus their Supply Chain (SC) strategies on quality and time-to-market. Although they are characterized by many different aspects, both leverage on the same point of strength: their internal Product Development $(\mathrm{PD})$ process. The opposite occurs in the automotive industry, with its standard and functional products and its efficient pipeline centred on cost reduction. Starting from previous works presented during the last PLM conference (PLM16), the research aims at investigating similarities and differences between these sectors, focusing on their PD process and their main critical success factors. Moreover, the authors analyse how Food and Fashion companies are managing the entire set of information throughout PD and the strategic role of Product Lifecycle Management (PLM). In order to reach these goals, a multiple case study analysis has been performed, involving companies belonging to the Food and Fashion industries. The results will be relevant both for academics and practitioners. Indeed, there is a literature gap about this topic, because of the lack of researches concerning Food and Fashion PD. From the practitioners point of view, the results of this work will help Food and Fashion companies to support their business analysing the PD process and to better understand how the use of the PLM system could improve it.
\end{abstract}

Keywords: Product Development (PD); Product Lifecycle Management (PLM); Food Industry; Fashion Industry; PLM for Food and Fashion, Food and Fashion.

adfa, p. 1, 2011.

(C) Springer-Verlag Berlin Heidelberg 2011 


\section{$1 \quad$ Introduction}

Product Development (PD) represents the core process for many industries focusing on product quality and innovation. Food and Fashion companies are trying to streamline this process in order to reduce time-to-market and to be competitive in the international scenario. The two sectors are particularly linked in Italy, where they embody parts of the three F (food, fashion and furniture) driving "Made in Italy" to its success, due to the innate history and culture, creativity, design and lifestyle [1]. In this concern, the Food and Fashion are the two sectors where Italians trust more concerning the "Made in Italy" brand [2].

At first glance, Food and Fashion appear to be different and distant environments, especially because of product features from the final customer viewpoint. The fashion industry stresses the not-essential customer needs, i.e. the ones related to the irrational sphere of our mind. On the other hand, the food industry produces, more than other sectors, vital items that every customer chooses day-by-day; yet it also delivers more "fashionable" products that clients could do without (in particular processed foods, as chocolate, sweets, jams and so on). Hence, fashion could be recognisable in all those products that satisfy emotional and temporary needs, including food products. Moreover, analysing both the supply chains from the companies' perspective, they prove to be configured as "market responsive" instead of "physically efficient" [3]: their primary purpose is to respond quickly to unpredictable demand. Other similarities are related to product design and management. According to Fisher [3], Food and Fashion deliver innovative products instead of functional ones, characterised by short lifecycles, high contribution margin and high variety. Furthermore, they are also special products instead of standard ones, as suggested by Christopher et al. [4]: they are not stable in demand and include a high level of customisation.

An interesting leitmotiv between Food and Fashion supply chains is that PD represents the core process; in fact, it is always conducted in-house to retain the control over the involved tasks and resources. In this context, the use of the PLM system in support of PD process for both industries could be considered as a key driver of innovation that allow them to be successful in the market. Starting from previous works presented during the last PLM conference (PLM16), this research aims at investigating similarities and differences between the Food and Fashion sectors, focusing on their PD process and on their main critical success factors. Moreover, the authors analyse how Food and Fashion companies are managing the entire set of information throughout PD and the strategic role of PLM. The second section of the paper explores the literature related to Food and Fashion supply chains and PLM functionalities in order to pave the way for the further case study analysis. Then, section 3 describes the methodology used to conduct the research and to obtain the main results, using both questionnaires and interviews. In the section 4 , the findings coming from the analysis of the interviews are shown. Finally, the paper concludes by presenting some thoughts and future research directions. 


\section{$2 \quad$ Literature review}

The first step within this study has been to gather as much information as possible about Food and Fashion supply chain chains, in order to distinguish the PD tasks and how they are linked with the other supply chain processes.

The fashion supply chain has been classified as agile [5] because it is market sensitive (closely connected to end-user trends), virtual (relying on shared information across all supply chain partners), network-based and process aligned (high degree of process interconnectivity between the network members). Food supply chain is not framed in a specific classification (e.g. lean or agile), but much interest is payed to its networked structure where producers, distributors and buyers/retailers [6][7]contribute to generate value. Food and Fashion supply chains are above all described through case studies [8][9][10][11][12][13][14] and their processes appears to be very business-specific, so that a diagram of a generic fashion or food supply chain is still missing.

The second step through the literature review has been devoted to the PLM functionalities supporting PD in the Food and Fashion industries.

For the fashion industry, in particular, PLM means clear visibility into PD, sourcing, and pre-production processes and a more collaborative approach, through every phase of the lifecycle. Even if PLM is spreading since a decade within the fashion industry, very little is known in literature about PLM features and functionalities, while most of the papers are related to automotive cases [15]. Just few authors [16][17], have discussed PLM implementation and adoption in fashion companies, highlighting the need for tailor-made functionalities.

PLM is becoming a very important solution also for the food industry. The use of this system allows food companies to provide different benefits, including: higher efficiency and productivity, increased product quality, reduced errors, greater profitability in PD and ensured regulatory compliance [18]. In this concern, several contributions dealing with themes related to the different phases of the product life cycle, (Beginning of Life BOL, Middle of Life MOL and End of Life EOL [19]) have been found in the scientific literature. It is also true that the term "product lifecycle management" [20] is a very broad topic [21][22]. Indeed, considering the entire life cycle of the product, PLM is not often used as a unique term but it is more common to find other terms that indicate one of its specific phase, a specific method or the software names used in the different stages. In conclusion, it could be said that the level of knowledge of the PLM systems is still low also in the food sector from the literature point of view. As a result, the major part of the publications concerning PLM in the Food and Fashion industries is actually based on analyses conducted by consulting societies and specialized magazines. The lack of papers about PD process and PLM functionalities in Food and Fashion industries has triggered a deeper investigation into several companies, through a case study analysis, in order to reach the objective of this study.

\section{$3 \quad$ Research methodology}

Case Study methodology has been adopted as research strategy. This works well with exploratory research because it can give those initial insights that are needed to find for the explorative cases [23]. In this work, multiple embedded case studies [24] have been 
applied to Food and Fashion companies. The aim of this study is to analyse the main Critical Success Factors (CSF) [25] in the two sectors, the PD activities [26] and how information are managed through PLM. In a first moment, the analysis has been held separately. In fact, two questionnaires with common topics and sections have been developed (customised for each specific sector) and then submitted to the selected companies to be investigated. Indeed, before to start the analysis, a common structure of the two questionnaires has been defined in order to obtain results that could be compared once the interview process was completed. The first step has been the identification of $\mathrm{CSF}$, which are a limited number of key variables or conditions that have an impact on how successfully and effectively an organization meets its mission or the strategic goals of a program or project. Then, the PD process has been analysed and linked to the PLM functionalities, in order to investigate both process and information management.

The questionnaire has been divided into three sections. After that, the questionnaire structure has been defined and adapted for each sector. The next step was to identify the reference sample, so that the two analyses could be compared. In order to achieve homogeneity in the sample, companies selected have to respect all the following requirements: constituting a brand managing finished products, being owned brands, having at least a BU in Italy and an international profile and being medium-large firms established in their business for several years. After this first screening, it was decided to select those companies that are: (i) conducting PD activities in-house; (ii) showing different market positioning based on price (from low-end to high-end companies); (iii) including, for food companies, "fashionable" factors in the product (as a packaging with a certain appealing, the choice of a specific ingredient just for a specific period trend, and whatever is not primary food).

At this point, two groups of companies operating in the food and in the fashion businesses have been selected.

The five fashion companies interviewed manage leather goods, shoes and ready to wear products. According to [27] the cases range from the luxury market segment (cases 1,2 and 3) to the lower-end brands (cases 4 and 5): this market segmentation is based on price levels. Case 1 and 3 conduct all the supply chain processes internally, while in the other cases production is outsourced to suppliers located in Italy and in Europe. Three cases have already implemented a PLM solution, while the remaining are using Product Data Management (PDM) and are evaluating to adopt PLM. Two main clusters have been identified: high-end/luxury companies, selling leather goods, prefer to focus on CSFs as quality and innovation and to retain in-house the majority of supply chain processes. They need to achieve innovation also in data management and have implemented an industry-specific PLM solution. The second cluster includes lowend companies, selling outerwear and childrenswear, that are competing on time to market (TTM) and decide to outsource production to suppliers. They are still not able to manage product information through PLM.

The seven food companies interviewed manage milk and yogurt, pasta and sauces and confectionery products. All the companies interviewed decided to outsource the distribution and sales phases. This is due to the fact that all the companies consider as core phases the $R \& D$, purchase and production: this is the reason why they decide to leave them internally, being the phases that add more value to the final product. 
Furthermore, food sector could be classified through different market segments basing on product categories: fresh products (case 1 and 5), pasta and canned food (case 2, 4 and 6) and confectionery products (case 3 and 7).

Moreover, just two companies are using the PLM system, while the remaining are adopting PDM and ERP. Some of the companies intend to adopt the PLM solution, while others do not even know the meaning of this system and the related benefits.

The selected companies have been contacted and asked for their willingness to be investigated through a case study; the companies analysed have been finally selected among those which indicated their availability for a field investigation. Case studies typically involve multiple sources of information [23]. In this research, they are: two questionnaires, which have been used as a guideline for many semi-structured interviews with the company's managers (IT and R\&D managers); semi-structured and open interviews (the latest coming from consulting activities). Both questionnaires have been earlier validated and tested. Then they have been sent to the company's IT and R\&D managers and discussed through an interview. The collected results have been elaborated and submitted to the company's managers for approval. In conclusion, the results obtained from the case studies have been validated by the company's top management. Once the responses of the two different questionnaires have been analysed, a comparison between Food and Fashion results has been performed and similarities and differences have been found.

\section{$4 \quad$ Findings}

This section describes the results coming from the case study analysis, deepening first of all the CSFs and challenges of the companies interviewed. Then, PD process, the related activities, data management and the role of PLM are analysed for both Food and Fashion industries.

\subsection{Critical Success Factors}

A background to acknowledge the strategic choices of the cases analysed is required to introduce the topics of PD and PLM in the Food and Fashion industries.

Fashion companies are orienting their efforts to improve products quality and to streamline their pipelines reducing TTM. Innovation is another important CSF, given the continuous progress entailed by new technologies and the attention paid by customers to digitalization. The luxury companies (cases $1,2,3$ ) also leverage lots of their strategic decisions on the craftsmanship behind the manufacturing process, and on the brand reputation. While, companies belonging to the low-end market segment (cases 4 and 5) try also to reduce costs, transferring the manufacturing process to countries with cheap labour. These strategic goals are accompanied with several challenges, as (i) the need to develop premium quality products, (ii) the importance of style and design, (iii) the "Made in Italy" origin and (iv) the increasingly shorter product lifecycle.

Concerning the food industry CSFs, companies are focusing more on: quality, costs, customer satisfaction and TTM. As in the Fashion industry, also for the food companies, innovation is considered a key factor to improve and to develop a new product, 
ensuring its success in the market. Companies operating in pasta and confectionery sectors (cases 2,3,4,6,7) are more focused on the innovation of the product, in terms of meaning (changing the aesthetic of the product and assigning a certain meaning to a certain product) [28]. The reason why they decide to bet to the innovation of the meaning is usually related to two main factors: the product is not a primary food (in fact they produce sweets and pasta) and/or the recipe complexity is low (few and standard ingredients). On the other hand, company producing fresh products (cases 1,5) are more focused on quality, customer satisfaction and nutritional factors. These companies produce products subject to high perishability and are addressing to very important and delicate markets (such as food for children or elderly). The food industry faces different challenges, such as: (i) retail consolidation, (ii) ineffective innovation, (iii) increasing regulatory requirements and unclear regulations, (iv) empowered consumers, (v) increasingly complex global supply chains, (vi) sustainability, (vii) TTM.

\subsection{PD activities, data management and PLM functionalities}

Interviews and direct contacts with $\mathrm{R} \& \mathrm{D}$ and IT managers have allowed to analyse business processes, with a particular focus on PD and on how information are managed throughout product lifecycle. Figure 1 and 2 represent outlines of processes, tasks, PLM functionalities and other software solutions that Food and Fashion companies have validated and approved in a general meaning. PD and production are the main processes that constitute the beginning of life for Food and Fashion products and that have a relationship to PLM. Sub-processes are also aligned in Food and Fashion cases: planning, recipe/collection development, prototyping and test, engineering and production are representative of all the companies interviewed. Information related to PLM functionalities, are based on the cases that are using it: they have implemented the same industry-specific solution, adding several customizations to the out-of-the box configuration.

\section{Results from fashion companies}

Concerning the fashion cases, PD begins with collection planning, when the Top management and Style managers take decisions about new collections, basing on budget, revenues, margins and analyses of market needs. Industry-specific PLM solutions include two main functionalities supporting collection planning, which are Merchandise Planning and Calendar: The Merchandise Planning module supports collection, product, and colourway planning by season to meet business objective. The Calendar module allows scheduling activities and milestones, both for products and materials. Office automation often completes data management with additional reports and aggregated information. Then, collection is developed: new products and carry over are identified, together with colourways and main materials. In PLM, the Product Specification module allows to define product details and build collections and the Material Management module is adopted to define materials, compositions labelling and material samples. At this stage, colour libraries are created, thanks to a specific PLM functionality, storing and grouping them by different criteria (e.g. season, collection, brand...). During the prototyping \& test stage, the fashion product is still in a preliminary status, based on a sketch and few details. A preliminary fitting, that test the prototypes on models, is performed for shoes and ready-to-wear products. In addition to the 
modules described for collection planning, the Technical sheets and BOM management functionality is adopted to create bill of materials and to link products and materials. Creative solutions and CAD (Computer Aided Design) constitute additional software to manage prototypes and are usually interfaced with PLM. When the product progresses to the engineering stage, it is a sample developed just in the base size but information about its costs and its components are defined. Size range management, Costing, Sourcing and Quality modules become important in PLM: the size maps are defined (they are particularly used for ready-to-wear products); information related to costs, suppliers, quotations, testing methods, procedures and expectations on materials and products are managed. During sales campaign, fashion companies are able to collect orders and to organize their production, whether it is conducted in house or outsourced to suppliers. PLM allows to arrange a collection book through a proper module, containing products approved during sales campaign, and, interfacing to the ERP, manages also the order entry. Only within the production stage, all the product information are definitive (colours, sizes, material consumptions, bill of materials, costs, packaging, care labels). In addition to the previously described modules, the Composition and care labels functionality permits to develop and edit product composition and it is often interfaced with labelling software solutions. Finally, the fashion product will be shipped to the warehouses and to the Retail or Wholesale channel for sales, but at this point PLM is not involved. Reports and Data packages are produced throughout the entire PD process, so a specific functionality has been provided in PLM. The same happens with team collaboration and user management: the system administrator may decide any time to assign specific privileges to groups of users, basing on the task they are in charge to.

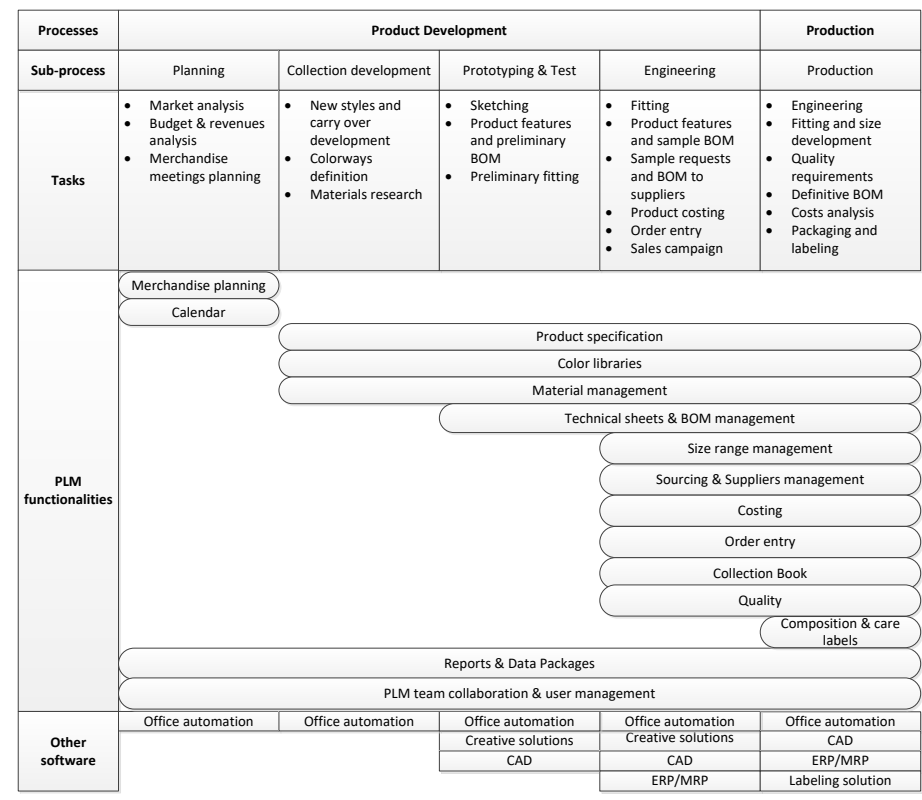

Fig. 1. Processes, tasks, PLM functionalities and other software in fashion companies 


\section{Results from food companies}

Concerning food companies, the PD process starts with the phase of planning. The process usually begins with a market analysis, in order to understand the customer needs, the competitor positioning, with the different comparisons with industry standards (benchmark) and so on. Once the external factors have been fully defined, the next step is to identify if there are already similar products in the company portfolio. A brainstorming on technical and economics features is conducted in order to identify the product characteristics. Then, a first feasibility phase has to be developed, in order to evaluate the idea, formulation, equipment, packaging and financial feasibility. When this phase is concluded, a product brief is defined. The PLM functionalities supporting this preliminary phase are: Product portfolio and data management (supporting the continuous cultivation of product sets by prioritizing and managing PD and retirements), PLM team collaboration (supporting the collaborations between different teams and company functions) and Report specific to the industry (enabling the facilitation, automation, and control of the entire development process). The second macro-phase that characterize the food PD process is the recipe development phase. The first activity characterizing this phase is the recipe development. Once the recipe has been developed, this undergoes various evaluation stadiums (usually internal), starting from a laboratory validation, then a pilot plant validation, the industrial plant and finally a legal validation. The PLM modules supporting this phase are: Specification management, Formula/recipe management and Regulatory compliance. Formula and recipe management solution sustains the recipe development and its management. Specification management allows to capture the descriptions and quantities of ingredients, materials and other content, including process information needed to produce, package and ship a product. Regulatory compliance enables to identify what regulations, policies and obligations are applicable to the developing product. These functionalities support all the next phases of the process. If the recipe passes all ratings, then it is possible to move to Prototyping \&Test phase. In this phase the production of the first prototypes is done observing if the realized products follow all the input specifications. A small batch of product is produced in order to be tasted both internally and externally. After that, the results of the tests will be analysed in order to understand whether changes to the recipe must be done. Therefore, a very important process characterizing this phase is the suppliers' selection. This phase is supported by the following PLM functionalities: Label and artwork management, Costing and Quality. Once the product is fully defined, it is possible to develop labels and artwork for different markets conforming to their preferences and regulations. Furthermore, product quality and costs are measured. These functionalities support the next PD phases, in order to constantly monitor costs and quality factors. The next macro-phase of the food PD process concerns the Engineering stage. The process owner verifies if the production line can handle the new product manufacturing. Different tests are performed, as industrial, quality, transportation and quantity tests. After that, quality tests must be done in order to check the quality of the industrialized products. It is usually produced a small number of products to check issues related to a small production. Finally, one or more transportation tests have to be done in order to understand how the product reacts to the various conditions during the different transports. Completed the Engineering phase, the actual production (bulk production) and the product launch are carried out. 


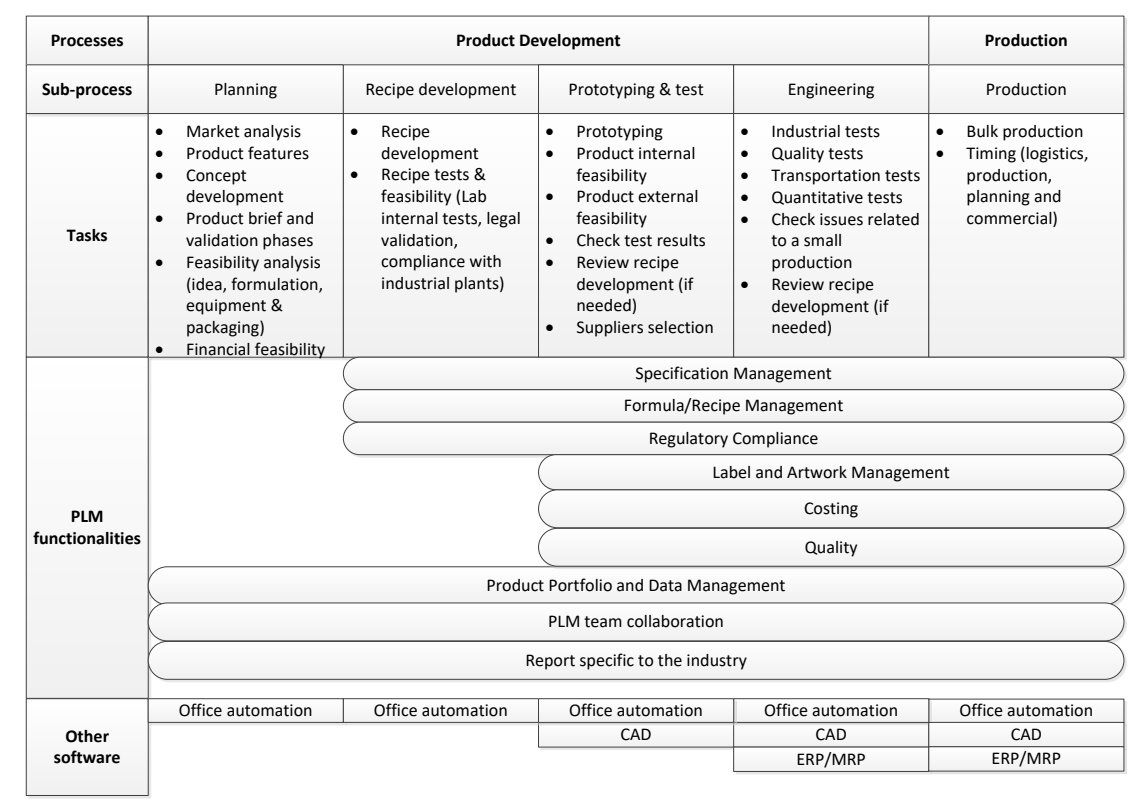

Fig. 2. Processes, tasks, PLM functionalities and other software in food companies

\subsection{Discussion: similarities and differences between Food and Fashion industries}

The parallel interviews to Food and Fashion companies are compared in this section and several similarities and differences, influencing process and information management, are outlined. The main similarities and differences are listed below:

Table 1. Food and Fashion Similarities and Differences

\begin{tabular}{ll}
\hline \multicolumn{1}{c}{ Similarities \& Differences } & \multicolumn{1}{c}{ Description } \\
\hline Importance of the PD process & $\begin{array}{l}\text { The case study has confirmed the relevance of PD in both } \\
\text { the industries. PD is characterized by the same number of } \\
\text { phases, assuming also the same meaning for both sectors }\end{array}$ \\
\hline Customer-centric product design & $\begin{array}{l}\text { Both the industries recognise the customer central role in } \\
\text { the PD process }\end{array}$ \\
\hline Importance of product innovation & $\begin{array}{l}\text { Fashion companies have demonstrated how innovation is } \\
\text { appealing for new consumers. Also, the food sector is fo- } \\
\text { cusing heavily on product innovation, which is gradually } \\
\text { becoming one of the key factors that characterize successful } \\
\text { food companies }\end{array}$ \\
\hline High number of items & $\begin{array}{l}\text { Food and Fashion companies manage lots of product varia- } \\
\text { tions, due to the high number of colourways for the fashion } \\
\text { industry, and to different packaging and market-related cus- } \\
\text { tomizations for the food industry }\end{array}$ \\
\hline
\end{tabular}




\begin{tabular}{|c|c|}
\hline $\begin{array}{l}\text { Importance of industry-specific PLM } \\
\text { solutions }\end{array}$ & $\begin{array}{l}\text { The cases have demonstrated that a general-purpose PLM } \\
\text { system is not able to fit the needs of Food and Fashion com- } \\
\text { panies. This is the typical situation in which "one size does } \\
\text { not fit all". Both the industries require several functionali- } \\
\text { ties that ask for an appropriate data model, provided by a } \\
\text { custom solution or an industry-specific PLM, developed by } \\
\text { a vendor with a particular focus on the sector }\end{array}$ \\
\hline \multicolumn{2}{|r|}{ Differences } \\
\hline Issues related to product obsolescence & $\begin{array}{l}\text { Food product lifecycle is highly influenced from obsoles- } \\
\text { cence and expiration dates while for fashion products, their } \\
\text { lifecycle length is just a matter of seasonality and new } \\
\text { trends }\end{array}$ \\
\hline $\begin{array}{l}\text { Issues related to regulatory compli- } \\
\text { ance }\end{array}$ & $\begin{array}{l}\text { PD in food companies cannot overlook regulatory compli- } \\
\text { ance and market constraints. This is not an issue in the fash- } \\
\text { ion industry }\end{array}$ \\
\hline Differences in the sale channels & $\begin{array}{l}\text { Fashion companies need to control the sales channels: the } \\
\text { large part is also managing the Retail channel, as brand } \\
\text { owners. Food companies sell their product to MRC (mass } \\
\text { retail channels), losing any control over the sales channel }\end{array}$ \\
\hline Differences in data model & $\begin{array}{l}\text { The typical fashion item is an SKU (stock keeping unit), } \\
\text { composed of a model, a colour and a size. The same struc- } \\
\text { ture is not replicated in the food products, which are char- } \\
\text { acterised by a recipe and the value-added information come } \\
\text { from the balancing quantities, more than from the single } \\
\text { components }\end{array}$ \\
\hline $\begin{array}{l}\text { Different customer perception of } \\
\text { product design }\end{array}$ & $\begin{array}{l}\text { Even if design is fundamental for both the industries cus- } \\
\text { tomers directly perceive product design in fashion items } \\
\text { while, for the food sector, the appealing design is associated } \\
\text { to the packaging more than to the product itself }\end{array}$ \\
\hline
\end{tabular}

\section{Conclusions and future research directions}

This study has investigated the core process within Food and Fashion supply chains, i.e. PD. The first analysis has been a literature review about the PD process, its main tasks and the role of PLM, as a software and as a strategic business approach. Academic research is poor in terms of contribution related to PD in the Food and Fashion industries. Hence, with the aim to analyse the main critical success factors in the two sectors, the PD activities and information management through PLM, a case study research has been performed. Two samples, one including fashion companies and the other one including food firms, have been identified and two different questionnaires (with the same structure) have been administered. The respondents from the fashion industry were high-end and low-end fashion companies: in three cases a PLM solution has been already implemented. The interviewed food companies managed different product categories (fresh products, pasta and canned food and confectionery products) and two cases have adopted a PLM solution. According to the case study analysis, the CSFs common to both the industries are product quality, TTM and innovation, while the challenges that these companies are facing appear to be more industry-specific. 
The interviews have also allowed to deepen how PD process and information are managed in Food and Fashion companies: activities, PLM functionalities and the interfaces with other software solutions have been detailed in Figure 1 and 2. Finally, a comparison between the two sectors has been performed, aiming at finding commonalities and differences. The main similarities that the authors have found are: importance of the PD process, customer-centric product design, importance of product innovation, high number of items managed and importance of industry-specific PLM solutions. Although, the following differences have been noticed: issues related to regulatory compliance, issues related to product obsolescence, differences in the sale channels, differences in data model and different customer perception of product design.

The results might be relevant for academics, because of the lack of researches concerning Food and Fashion PD. From the practitioners' point of view, the results of this work will help Food and Fashion companies to support their business, analysing the PD process and to better understand how the use of the PLM system could improve it.

A cross fertilization may be an interesting development of this research, allowing fashion companies to learn best practices related to PD and PLM from food firms and vice versa: for example, fashion products might be refined in their packaging and food industry might learn from the fashion product capability to be often renewed. Moreover, if we consider a particular merchandise category within the fashion industry, i.e. cosmetics, more commonalities will be found with the food companies, as the importance of regulatory issues. Cosmetics and food are also similar in terms of data model, because products are recipe-based, so that several PLM vendors have developed solutions fitting both the industries. A case study analysis might be performed in cosmetics companies, for their "fashion" nature and their affinity with food products. Other topics will be examined with a cross-industry approach: PD and PLM KPIs, PLM data model and the concept of "lean value chain". Finally, in order to close the examination of the three F driving "Made in Italy" to its success, several cases related to the Furniture industry might be included and analysed.

\section{$6 \quad$ References}

1. G. Aiello, R. Donvito, L. Grazzini, C. Halliburton, B. Wagner, J. Wilson, B. Godey, D. Pederzoli, and I. Shokola, "An international comparison of 'Made in Italy' in the fashion, furniture and food sectors: An observational research study in France, Russia and The United Kingdom,” J. Glob. Fash. Mark., vol. 6, no. 2, pp. 136-149, 2015.

2. Coldiretti, "I valori dell'agroalimentare italiano nell'indagine Coldiretti-Swg (16-102009),” 2009. [Online]. Available: http://www.coldiretti.it/News/Pagine/770---16-102009.aspx.

3. M. Fisher, "What is the right supply chain for your product.pdf," in Harvard Business Review, 1997, vol. 2, pp. 105-16.

4. M. Christopher, H. Peck, and D. R. Towill, "A taxonomy for selecting global supply chain strategies," The, vol. 17, no. 2, pp. 277-287, 2006.

5. M. Christopher, R. Lowson, and H. Peck, "Creating agile supply chains in the fashion industry.," Int. J. Retail Distrib. Manag., vol. 32, no. 8, pp. 367-376, 2004.

6. J. D. Bloom and C. C. Hinrichs, "Moving local food through conventional food system infrastructure: Value chain framework comparisons and insights," Renew. Agric. Food Syst., vol. 26, no. 1, pp. 13-23, 2011. 
7. J. G. Van Der Vorst, "Chapter 2: Performance Measurement in Agri-Food Supply Chain Networks, An Overview," Quantifying agri-food supply Chain, pp. 13-24, 2006.

8. G. Gereffi and J. Lee, "A Global Value Chain Approach to Food Safety and Quality Standards," America (NY)., vol. Global Hea, p. 52, 2009.

9. D. H. Taylor, "Value chain analysis: an approach to supply chain improvement in agri-food chains.," Int. J. Phys. Distrib. Logist. Manag., vol. 25, no. 10, pp. 744-761, 2005.

10. J. G. A. J. van der Vorst, A. J. M. Beulens, W. de Wit, and P. van Beek, "Supply Chain Management in Food Chains: Improving Performance by Reducing Uncertainty," Int. Trans. Oper. Res., vol. 5, no. 6, pp. 487-499, 1998.

11. A. K. Zokaei and D. W. Simons, "Value chain analysis in consumer focus improvement: A case study of the UK red meat industry," Int. J. Logist. Manag., vol. 17, pp. 141-162, 2006.

12. M. Christopher, "The Agile Supply Chain," Ind. Mark. Manag., vol. 29, no. 1, pp. 37-44, 2000.

13. A. Şen, "The US fashion industry: A supply chain review," Int. J. Prod. Econ., vol. 114, no. 2, pp. 571-593, 2008.

14. L. Barnes and G. Lea-Greenwood, "Fast Fashioning the supply chain: shaping the research agenda," J. Fash. Mark. Manag., vol. 10, no. 3, pp. 259-271, 2006.

15. E. d'Avolio, R. Bandinelli, and R. Rinaldi, "Improving new product development in the fashion industry through product lifecycle management: a descriptive analysis," Int. J. Fash. Des. Technol. Educ., vol. 8, no. 2, pp. 108-121, May 2015.

16. F. Segonds, F. Mantelet, J. Nelson, and S. Gaillard, "Proposition of a PLM tool to support textile design: A case study applied to the definition of the early stages of design requirements," Comput. Ind., vol. 66, pp. 21-30, 2015.

17. M. Jacob and E. Jonnro, "The drivers and factors influencing PLM adoption and selection," no. September, 2015.

18. G. H. Young, "PLM AND THE FOOD \& BEVERAGE INDUSTRY Conquering the Food Proving Value at Heinz," Agile Software Corporation. 2004.

19. D. Kiritsis, A. Bufardi, and P. Xirouchakis, "Research issues on product lifecycle management and information tracking using smart embedded systems," Adv. Eng. Informatics, vol. 17, no. 3-4, pp. 189-202, 2003.

20. S. Terzi, A. A. Bouras, D. Dutta, M. Garetti, D. Kiritsis, and M. Garetti, "Product lifecycle management \&amp;ndash; from its history to its new role," Int. J. Prod. Lifecycle Manag., vol. 4, no. 4, pp. 360-389, 2010.

21. G. Schuh, H. Rozenfeld, D. Assmus, and E. Zancul, "Process oriented framework to support PLM implementation," Comput. Ind., vol. 59, no. 2-3, pp. 210-218, 2008.

22. F. Ameri and D. Dutta, "Product lifecycle management: Closing the knowledge loops," Comput. Aided. Des. Appl., vol. 2, no. 5, pp. 577-590, 2005.

23. R. K. Yin, Case Study Research Design and Methods, 4th ed., vol. 5. 2009.

24. R. K. Yin, "Case Study Research . Design and Methods," SAGE Publications, vol. 26, no. 1. pp. 93-96, 2003.

25. R. Cooper and E. Kleinschmidt, "Benchmarking the firm's critical success factors in new product development," J. Prod. Innov. Manag., vol. 12, pp. 71-85, 1995.

26. R. G. . B. Cooper and E. J. . Kleinschmidt, "Winning businesses in product development: The critical success factors," Res. Technol. Manag., vol. 50, no. 3, pp. 52-66, 2007.

27. S. Saviolo and S. Testa, Le imprese del sistema moda: Il management al servizio della creatività. Etas, 2005.

28. R. Verganti, "Design, meanings and radical innovation: A research agenda," J. Prod. Innov. Manag., vol. 25, no. 5, pp. 436-456, 2008. 